structure factor $S(q)$. However, for $q \rightarrow 0$, a peak develops and grows with decreasing $T$, again demonstrating the presence of increasing long-range behaviour for $G_{u}\left(r, \Delta t^{*}\right)$. No such growing peak at $q=0$ appears in $S(q)$ (Fig. 4, inset). By analogy with conventional critical phenomena, we have attempted to fit $S_{u}\left(q, \Delta t^{*}\right)$ by an OrnsteinZernike form, $S_{u}(q) \propto 1 /\left(1+\xi^{2} q^{2}\right)$, where $\xi$ is the correlation length ${ }^{16}$. This form fits well at the highest $T$, but fails on approaching $T_{\mathrm{c}}$, possibly because of finite size effects. Larger simulations may be required to determine accurately the correct functional form for $S_{u}$ at small $q$. Nevertheless, the data show unambiguously that as $T \rightarrow T_{c}$, spatial correlations between the displacement of monomers become increasingly long-ranged.

Our simulations reveal a dynamical length scale relevant both to the mode-coupling dynamical transition and the glass transition. In this way we provide a bridge between the phenomenon of dynamical heterogeneity and current theories of supercooled liquids and vitrification. Remarkably, our findings are qualitatively identical to new results for simulated $\mathrm{Ni}_{80} \mathrm{P}_{20}$, a model metallic glassformer ${ }^{14}$, showing that the correlated monomer motion above $T_{\mathrm{c}}$ is neither due to nor strongly affected by chain connectivity. Instead, the striking similarity between $\mathrm{Ni}_{80} \mathrm{P}_{20}$ and the present polymer melt suggests that correlated motion is a universal feature of (at least fragile $^{1}$ ) glass-forming liquids. Furthermore, we have identified a fluctuating dynamical variable $U$ in this polymer melt whose fluctuations become long-ranged and appear to diverge at $T_{\mathfrak{c}}$, and which thus behaves much like a static order parameter on approaching a second-order phase transition-albeit one that is not obviously accessible to traditional scattering experiments, but may be measurable in optical microscopy experiments on colloidal suspensions. Our findings suggest that substantial shifts in $T_{\mathrm{c}}$ could be observed by confining glass-forming liquids and melts, thereby limiting the divergence that can occur. Whether this could also explain the confinement-induced shifts of $T_{\mathrm{g}}$ observed experimentally ${ }^{22-26}$ needs to be investigated. Our results indicate that it may be possible to obtain further insight into the nature of supercooled, glass-forming liquids using an extension to dynamically defined quantities of the framework of ordinary critical phenomena.

Received 15 December 1998; accepted 2 March 1999.

1. Ediger, M. D., Angell, C. A. \& Nagel, S. R. Supercooled liquids and glasses. J. Phys. Chem. 100, 13200 $13212(1996)$

Yip, S. \& Nelson, P. (eds) Transport Theory. Stat. Phys. 24, 755-1270 (1995).

3. Götze, W. \& Sjögren, L. The mode coupling theory of structural relaxations. Transport Theory Stat. Phys. 24, 801-853 (1995)

4. Hiwatari, Y. \& Muranaka, T. Structural heterogeneity in supercooled liquids and glasses. J. Non-Cryst. Solids 235-237, 19-26 (1998)

5. Perera, D. \& Harrowell, P. A two-dimensional glass: microstructure and dynamics of a 2D binary mixture. J. Non-Cryst. Solids 235-237, 314-319 (1998).

6. Onuki, A. \& Yamamoto, Y. Kinetic heterogeneities and non-linear rheology of highly supercooled liquids. J. Non-Cryst. Solids 235-237, 34-40 (1998)

. Doliwa, B. \& Heuer, A. Cage effect, local anisotropies, and dynamic heterogeneities at the glass transition: a computer study of hard spheres. Phys. Rev. Lett. 80, 4915-4919 (1998).

8. Kob, W., Donati, C., Plimpton, S. J., Poole, P. H. \& Glotzer, S. C. Dynamical heterogeneities in supercooled Lennard-Jones liquid. Phys. Rev. Lett. 79, 2827-2930 (1997).

9. Donati, C. et al. String-like clusters and cooperative motion in a model glass-forming liquid. Phys. Rev. Lett. 80, 2338-2341 (1998).

10. Donati, C., Glotzer, S. C., Poole, P. H., Kob, W. \& Plimpton, S. J. Spatial correlations of mobility and immobility in a glass-forming Lennard-Jones liquid. Phys. Rev. E. (submitted).

11. Böhmer, R. et al. Nature of the non-exponential primary relaxation in structural glass-formers probed by dynamically selective experiments. J. Non-Cryst. Solids 235-237, 1-9 (1998).

12. Cicerone, M. T., Blackburn, F. \& Ediger, M. D. Anomalous diffusion of probe molecules in polystyrene: evidence for spatially heterogeneous segmental dynamics. Macromolecules 28, 82248232 (1995).

13. Hansen, J. P. \& McDonald, I. R. Theory of Simple Liquids (Academic, London, 1986)

14. Donati, C., Glotzer, S. C. \& Poole, P. H. Growing spatial correlations of particle displacements in a simulated liquid on cooling toward the glass transition. Phys. Rev. Lett. (in the press).

15. Glotzer, S. C., Jan, N., Lookman, T., MacIsaac, A. B. \& Poole, P. H. Dynamical heterogeneity in the Ising spin glass. Phys. Rev. E 57, 7350-7353 (1998).

16. Stanley, H. E. Introduction to Phase Transitions and Critical Phenomena (Oxford University Press, New York, 1971).

17. van Blaaderen, A. \& Wiltzius, P. Real-space structure of colloidal hard-sphere glasses. Science $\mathbf{2 7 0}$ $1177-1179(1995)$

18. Leheny, R. L. et al. Structural studies of an organic liquid through the glass transition. J. Chem. Phys. 105, 7783-7794 (1996)

19. Bennemann, C., Paul, W., Binder, K. \& Dünweg, B. Molecular-dynamics simulations of the thermal glass transition in polymer melts: $\alpha$-relaxation behavior. Phys. Rev. E 57, 843-851 (1998).

20. Bennemann, C., Baschnagel, J. \& Paul, W. Molecular-dynamics simulation of a glassy polymer melt: incoherent scattering function. Eur. Phys. J. B (in the press).
21. Bennemann, C., Paul, W., Baschnagel, J. \& Binder, K. Investigating the influence of different thermodynamic paths on the structural relaxation in a glass forming polymer melt. J. Phys. Cond. Mat. (in the press).

22. Jerome, B. \& Commandeur, J. Dynamics of glasses below the glass transition. Nature 386, 589-592 (1997).

23. Forrest, J. A., Dalnoki-Veress, K. \& Dutcher, J. R. Interface and chain confinement effects on the glass transition temperature of thin polymer films. Phys. Rev. E 56, 5705-5515 (1997)

24. Wallace, W. E., van Zanten, J. H. \& Wu, W.L. Influence of an impenetrable interface on a polymer glass-transition temperature. Phys. Rev. E 52, R3329-R3332 (1995).

25. Jackson, C. L. \& McKenna, G. B. The glass transition of organic liquids confined to small pores. J. NonCryst. Solids 131-133, 221-224 (1991).

26. Arndt, M., Stannarius, R., Groothues, H. \& Kremer, F. Length scale of cooperativity in the dynamic glass transition. Phys. Rev. Lett. 79, 2077-2080 (1997).

Correspondence and requests for materials should be addressed to S.C.G. (e-mail: sharon.glotzer@ nist.gov).

\section{Global changes in intensity of the Earth's magnetic field during the past $800 \mathrm{kyr}$}

\section{Yohan Guyodo ${ }^{\star} \boldsymbol{\&}$ Jean-Pierre Valet ${ }^{\star}$}

Institut de Physique du Globe de Paris, UMR CNRS 7577, 4, Place Jussieu, 75262 Paris Cedex 05, France

Recent advances in palaeomagnetic and dating techniques have led to increasingly precise records of the relative intensity of the Earth's past magnetic field at numerous field sites. The compilation and analysis of these records can provide important constraints on changes in global magnetic field intensity and therefore on the Earth's geodynamo itself. A previous compilation for the past $200 \mathrm{kyr}$ integrated 17 marine records into a composite curve $^{1}$, with the geomagnetic origin of the signal supported by an independent analysis of ${ }^{10} \mathrm{Be}$ production made on different cores ${ }^{2}$. The persistence of long-term features in the Earth's magnetic intensity or the existence of long-term periodic changes cannot, however, be resolved in this relatively short time span. Here we present the integration of 33 records of relative palaeointensity $y^{3-19}$ into a composite curve spanning the past $800 \mathrm{kyr}$. We find that the intensity of the Earth's dipole field has experienced large-amplitude variations over this time period with pronounced intensity minima coinciding with known excursions in field direction, reflecting the emergence of non-dipole components. No stable periodicity was found in our composite record and therefore our data set does not support the hypothesis that the Earth's orbital parameters have a direct and strong influence on the geodynamo.

We constructed the database (Table 1) by selecting records obtained after appropriate normalization of magnetization intensity. All the studies have been published with the exception of a high-resolution sequence from core ODP- $1021^{18}$. In addition to the data involved in the composite curve' referred to above ('Sint200 '), the present selection includes 16 new records relatively well distributed around the globe, 10 of which document the interval $600-800$ kyr ago (Table 1). In most cases, dating was obtained by correlation to reference curves of oxygen-isotope $\left(\delta^{18} \mathrm{O}\right)$ variations or other palaeoclimate proxies such as low field susceptibility or density. The age model defined by the $\delta^{18} \mathrm{O}$ reference curve of Bassinot et al. ${ }^{20}$ has been applied to records older than $300 \mathrm{kyr}$; the reference curve of Martinson et al. ${ }^{21}$ was preferred for records younger than $300 \mathrm{kyr}$ because of its higher resolution. An alternative approach was used for three cores (RC10-167, KS87-752 and P226) with no obvious correlation between the palaeoclimate proxies and the $\delta^{18} \mathrm{O}$ reference curve. Following previous studies ${ }^{1,10}$, these individual records of palaeointensity were correlated with a preliminary stack derived from the other well dated curves. In a second

$\dagger$ Present address: Department of Geology, University of Florida, Gainesville, Florida 32611, USA. 
Table 1 Records involved in the construction of Sint-800

\begin{tabular}{|c|c|c|c|c|c|c|c|c|}
\hline Record & $\begin{array}{l}\text { Lat. } \\
\left({ }^{\circ} \mathrm{N}\right)\end{array}$ & $\begin{array}{l}\text { Long. } \\
\left({ }^{\circ} \mathrm{E}\right)\end{array}$ & $\begin{array}{l}\text { Sed. rate } \\
\left(\mathrm{cm} \mathrm{kyr}^{-1}\right)\end{array}$ & $\begin{array}{l}\text { Normalization } \\
\text { parameter }\end{array}$ & $\begin{array}{l}\text { Other coherent } \\
\text { normalization }\end{array}$ & Dating & $\begin{array}{c}\text { Interval used } \\
(\mathrm{kyr})\end{array}$ & Ref. \\
\hline \multicolumn{9}{|l|}{ Set no. 1} \\
\hline KET82-51 & 39 & 14 & 6.2 & $\chi$ & ARM, SIRM & Corr. with KET8004 + tephra. & $10-90$ & 3 \\
\hline MD84-629 & 36 & 33 & 11.6 & $\chi$ & ARM, SIRM & $\delta^{18} \mathrm{O}+$ tephra. & $20-60$ & 3 \\
\hline DED87-707 & 40 & 13 & 10.4 & 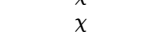 & ARM, SIRM & Corr. with KET8004 + tephra. & $10-60$ & 3 \\
\hline MD85-668 & -1 & 46 & 6.2 & $\hat{A R M}$ & $\chi, \mathrm{IRM}$ & $\delta^{18} \mathrm{O}$ & $20-140$ & 4 \\
\hline MD85-669 & 2 & 47 & 5.3 & ARM & $\chi, I R M$ & $\chi$ corr. with MD668 & $20-140$ & 4 \\
\hline MD85-674 & 3 & 50 & 10.9 & ARM & $\chi, I R M$ & $\chi$ corr. with MD668 & $20-140$ & 4 \\
\hline ERDC113P & 2 & 159 & 1.2 & $\chi$ & & $\delta^{18} \mathrm{O}$ & $10-360$ & 5,6 \\
\hline NGC29 & 4 & 136 & 2.4 & ARM & $\chi$ & $\chi$ correlated with NP5 & $0-190$ & 7 \\
\hline NGC26 & 2 & 135 & 3.7 & ARM & $\chi$ & $\chi$ correlated with NP5 & $0-120$ & 7 \\
\hline NGC16 & 2 & 135 & 3.7 & ARM & $x$ & $\chi$ correlated with NP5 & $0-190$ & 7 \\
\hline NP7 & 1 & 138 & 2.0 & ARM & $\chi$ & $\chi$ correlated with NP5 & $10-200$ & 7 \\
\hline NP5 & 1 & 136 & 3.7 & ARM & 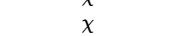 & $\delta^{18} \mathrm{O}$ & $10-200$ & 7 \\
\hline SU92-18 & 37 & -27 & 3.5 & ARM & $\chi, \widehat{S I R M}$ & $\delta^{18} \mathrm{O}$ & $0-280$ & 8 \\
\hline SU92-19 & 37 & -27 & 3.2 & ARM & $\chi$, SIRM & Reflectance $+\chi$ correlated with SU92-18 & $0-280$ & 8 \\
\hline ODP-768A & 8 & 121 & 9 & $\chi$ & ARM, IRM & $\delta^{18} \mathrm{O}+\mathrm{AMS}$ radiocarb. & $10-90$ & 9 \\
\hline ODP-768B & 8 & 121 & 10 & $\hat{x}$ & ARM, IRM & $\delta^{18} \mathrm{O}+\mathrm{AMS}$ radiocarb. & $10-130$ & 9 \\
\hline ODP-769B & 8 & 121 & 8.2 & $x$ & ARM, IRM & $\delta^{18} \mathrm{O}+\mathrm{AMS}$ radiocarb. & $10-160$ & 9 \\
\hline P012 & 58 & -47 & 10 & IRM & $\chi, A R M$ & $\delta^{18} \mathrm{O}+\mathrm{AMS}$ radiocarb. + calib. Sint-200 & $10-180$ & 10 \\
\hline P013 & 58 & -48 & $10-30$ & IRM & $\chi, A R M$ & $\delta^{18} \mathrm{O}+\mathrm{AMS}$ radiocarb. + calib. Sint-200 & $10-220$ & 10 \\
\hline P094 & 50 & -45 & 10 & IRM & $\chi, A R M$ & $\delta^{18} \mathrm{O}+\mathrm{AMS}$ radiocarb. + calib. Sint-200 & $0-110$ & 10 \\
\hline \multicolumn{9}{|l|}{ Set no. 2} \\
\hline ODP-983 & 60 & -24 & 10.4 & IRM & $\chi, A R M$ & $\delta^{18} \mathrm{O}$ & $0-725$ & 11 \\
\hline ODP-984 & 61 & -24 & 12.6 & IRM & $\chi, A R M$ & $\delta^{18} \mathrm{O}$ & $0-450$ & 11 \\
\hline KS87-752 & -38 & -38 & 2.4 & ARM & $\chi$ & $\chi$ corr. with ODP940 & $310-800$ & 12 \\
\hline ODP769 & 9 & 121 & 13 & $\chi$ & ARM, IRM & $\delta^{18} \mathrm{O}$ & $200-800$ & 13 \\
\hline NP35 & 4 & 141 & 1 & ARM & IRM & $\delta^{18} \mathrm{O}$ & $130-700$ & 14 \\
\hline RNDB75P & 2 & 160 & 1.5 & IRM & $\chi, \mathrm{ARM}$ & $\delta^{18} \mathrm{O}$ & $120-670$ & 6 \\
\hline MD940 & -6 & 61 & 1.3 & ARM & $\chi, \mathrm{IRM}$ & $\chi$ corr. with ODP709 & $100-800$ & 15 \\
\hline ODP851 & 2 & -110 & 1.8 & ARM & $\chi, I R M$ & GRAPE, astro. calib. & $30-800$ & 16,17 \\
\hline P226 & 3 & -169 & 0.6 & ARM & IRM & $\mathrm{B} / \mathrm{M}$ reversal & $40-780$ & 14 \\
\hline ODP1021 & 40 & -128 & 3.7 & $\chi$ & ARM & $\chi$, astro. calib. & $10-800$ & 18 \\
\hline NGC38 & -15 & -175 & 1 & ARM & IRM & $\delta^{18} \mathrm{O}$ & $10-400$ & 14 \\
\hline RC10-167 & 33 & -150 & 2.1 & ARM & & $\mathrm{B} / \mathrm{M}$ reversal & $0-800$ & 19 \\
\hline NGC36 & 1 & 160 & 1 & ARM & IRM & $\delta^{18} \mathrm{O}$ & $0-550$ & 14 \\
\hline
\end{tabular}

, magnetic susceptibility; ARM, anhysteretic remanent magnetization; IRM, isothermal remanent magnetization.

Data available as Supplementary Information.

step, the age models were applied to the susceptibility records and subsequently refined with respect to the $\delta^{18} \mathrm{O}$ reference curve. This procedure increased the quality of the correlation by a factor of two. All the records have been linearly interpolated every 1 kyr before calculation of the stack.
Palaeointensity variations can be extracted from natural remanent magnetization (NRM) after normalization of the intensity by an appropriate magnetic parameter which activates the same magnetic fraction as that which carries the NRM. However, various magnetic parameters and different magnetization levels have been

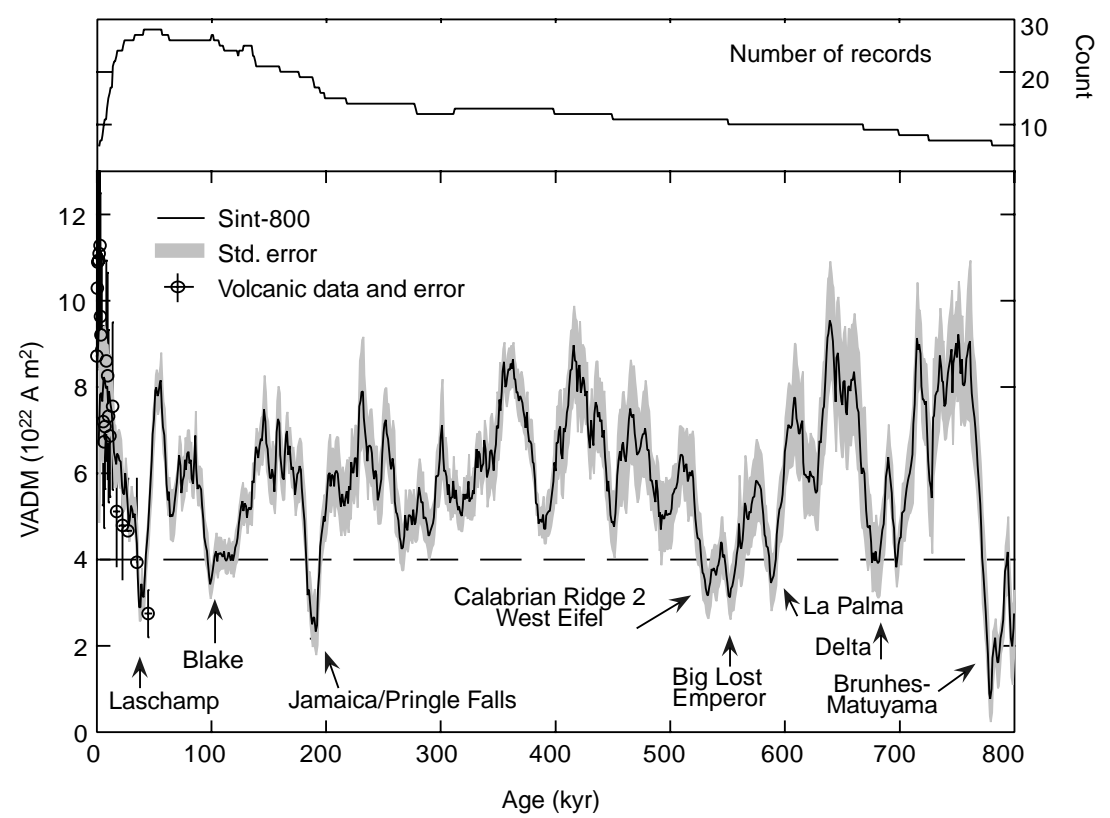

Figure 1 Synthetic record (Sint-800) with its standard error obtained from the stack of 33 records of palaeointensity. The upper part of the figure gives the number of records within successive time intervals. All the records have been dated with a common timescale and normalized (see text). The curve has been calibrated over the past $40 \mathrm{kyr}$ in terms of virtual axial dipole moments (VADMs)

using averaged volcanic data (open circles) over 5-kyr intervals (correlation coefficient, $r=0.7$ ). The horizontal dashed line corresponds to the critical value of intensity below which directional excursions have been observed (Langereis et al. ${ }^{25}$ ). Other dips of lower amplitude coincide also with excursions reported from marine sediments. 


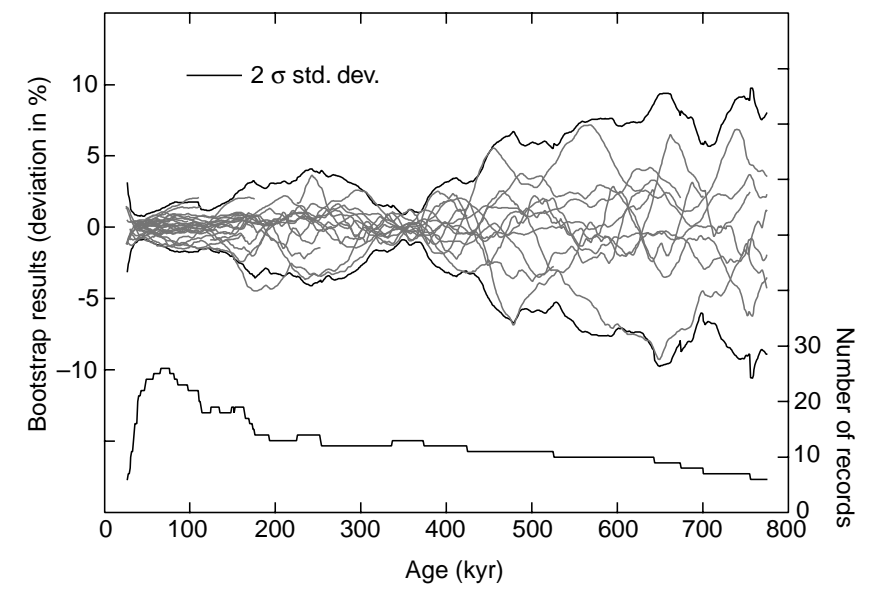

Figure 2 Tests of our synthetic record, Sint-800. Shown are results of a bootstrap process aimed at identifying drawings of 33 different composite records that show significant deviations from Sint-800. Each plot corresponds to the divergence between Sint-800 and another composite calculated after removing one record from the database. No outlier can be identified.

used by authors. Integration of the records on a common scale can therefore only be done after division of the intensities by their mean value over the entire time interval. This simple procedure accounts also for the latitudinal dependence of the dipole field intensity. As the average geomagnetic field was probably different over different periods, this normalization should be done over the same time interval for all the records. Unfortunately, no time interval is common to the entire data set which was thus split into two different groups. Records from the first group (Table 1) are younger than $350 \mathrm{kyr}$ and they were normalized to unity over the interval 24-56 kyr ago. The interval 312-398 kyr ago was used for the second group. Subsequently, two independent stacks were constructed and compared over the common interval 0-350 kyr. Final integration of the two data sets was obtained after correcting the records of the first group by a factor 0.84 , which corresponds to the ratio between the two averaged values.

In Fig. 1 we show our composite record 'Sint-800' and the associated standard error obtained after stacking all the data. In the same figure are plotted also the number of records involved over each successive time interval. The stability of the results has been tested by a bootstrap technique similar to that used for Sint-200. No significant discrepancy was observed between the stacks performed from 33 successive calculations. Deviations between Sint-800 and each successive drawing (after smoothing with a 50-kyr-long moving window to slightly reduce the resolution) lie within the limits imposed by the $2 \sigma$ standard deviation (Fig. 2 ) and confirm the absence of significant outliers. We also note that the sharpness of the distribution is related to the number of records. Thus, some refinement (mainly a reduction of the uncertainties) would be produced by incorporation of future records covering the interval 500-800 kyr ago. Conversion into virtual axial dipole moments (VADMs) were done using volcanic records of absolute palaeointensity. Volcanic data must be averaged out over finite time intervals in order to eliminate the contribution of the non-dipole field. Only the period $0-40 \mathrm{kyr} \mathrm{ago}^{22}$ is sufficiently documented to allow this. According to this calibration, the highest intensities culminate at about $9 \times 10^{22} \mathrm{~A} \mathrm{~m}^{2}$ and the time-averaged field value during the Brunhes chron was $(6.0 \pm 1.5) \times 10^{22} \mathrm{~A} \mathrm{~m}^{2}$.

One characteristic of Sint-800 (Fig. 1) is that many intensity lows occurred during the past 800 kyr. Sint- 800 was constructed from world-wide marine records with a resolution that does not exceed $3-5 \mathrm{kyr}$ and is thus sensitive to the variations of the axial dipole moment. A simple condition for the occurrence of excursions ${ }^{23,24}$ is that the dipole field remains abnormally low so that non-dipole

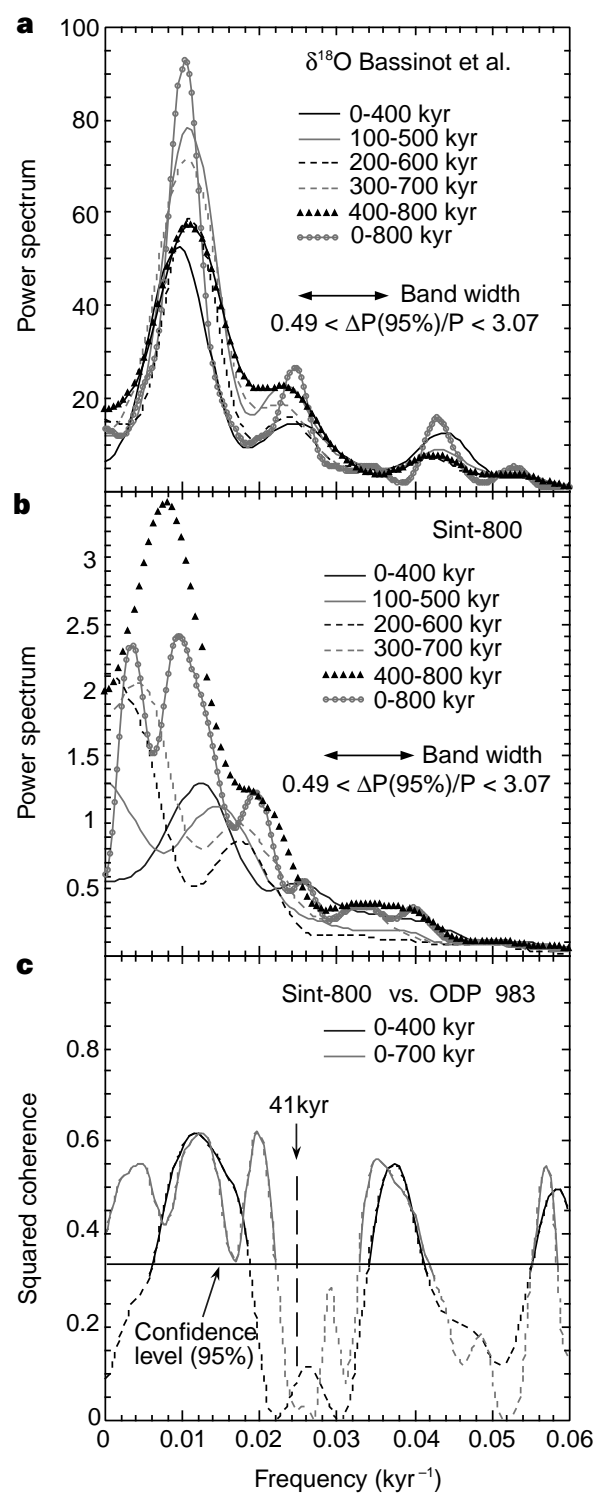

Figure 3 Spectral analysis of Sint-800 using the Blackman-Tukey method with a Bartless window. a, b. Power spectra of the $\delta^{18} \mathrm{O}$ curve ${ }^{20}(\mathbf{a})$ and Sint-800 (b). Analyses have been performed over different time intervals (to explore the stability of the results). There is no stationarity or periodicity emerging from the palaeointensity variations. c, Coherence function between Sint-800 and ODP Site 983 (ref. 11). The calculations involve the entire $0-700 \mathrm{kyr}$ interval common to the two curves and then only the $0-400 \mathrm{kyr}$ interval which incorporates more records.

effects become dominant. We referred to the analysis of the short events by Langereis et al. ${ }^{25}$ to select all the excursions that have been previously reported from both sedimentary and volcanic records. To those we added the discovery ${ }^{26}$ of a large field excursion data at $595 \pm 14 \mathrm{kyr}$ ago from a volcanic sequence at La Palma. All these events coincide with periods of significant intensity drops (Fig. 1) and occur below a critical field of $\sim 4 \times 10^{22} \mathrm{~A} \mathrm{~m}^{2}$, that is, less than $50 \%$ of the present-day field. In fact, a reduction of the present-day dipole intensity by this amount would induce the emergence of non-dipole components at many locations ${ }^{25,27}$. Other excursions reported from marine sediments $\mathrm{s}^{23,25,27}$ are synchronous with dips of lower amplitude. There is no correlation between these intensity dips and cold climate events, although such a correlation has been suggested $^{28}$.

The possibility that the geomagnetic field variations would be modulated by the Earth's orbital parameters has been suggested by 
several authors ${ }^{29-32}$. Nevertheless, most studies dealing with long and well dated sequences conclude either that a 30-50 kyr geomagnetic pulse $\mathrm{e}^{5,6}$ exists, or that there is no dominant period. But a correlation has been found ${ }^{11}$ between the 41 -kyr obliquity cycle and palaeointensity variations; this was based on the analysis of a very detailed and precisely dated sequence ${ }^{11}$ from Ocean Drilling Project Site 983 . We performed a spectral analysis of Sint-800 using the Blackman-Tukey technique with the AnalySeries software ${ }^{33}$. In order to investigate the stability of the results, we first analysed the entire signal and then restrained the analysis to the $0-400 \mathrm{kyr}$ interval which incorporates more records. The spectral contents of these two intervals are significantly different. The same conclusion is reached by comparing every 400 -kyr-long interval in increments of $100 \mathrm{kyr}$ with the $0-800 \mathrm{kyr}$ period (Fig. 3 ). These results point out the absence of any dominant stable periodicity. For comparison, the same analysis performed with the $\delta^{18} \mathrm{O}$ curve $\mathrm{e}^{20}$ shows perfect reproducibility of the orbital peaks $(23,41$ and $100 \mathrm{kyr})$ over each interval. (An additional indication supporting these conclusions is that the artificial 41-kyr signal created after band-pass-filtering Sint800 has a different phase and a much smaller amplitude than the signal obtained by the same procedure for site 983.) Similar observations and conclusions are reached without incorporating the site 983 record in the database. Orbital modulation of the geomagnetic field should primarily affect the dipole field, and therefore should be present in Sint- 800 which incorporates at least 20 data points per $41 \mathrm{kyr}$. However, for periods shorter than $40 \mathrm{kyr}$ it is possible that uncertainties due to dating and/or smoothing inherent to the stacking process induced loss of spectral power (Fig. 3b). This may explain the pattern observed in the coherence functions between Sint-800 and data from site 983 (Fig. 3c) for these short periods.

Our composite Sint- 800 curve shows that the Earth's dipole field over the past $800 \mathrm{kyr}$ was dominated by changes of very large (and various) amplitude but does not indicate the presence of any dominant periodicity. The mean field value remained more or less constant. Geomagnetic excursions are observed when the dipole moment decreases to a critical value of about $4 \times 10^{22} \mathrm{~A} \mathrm{~m}^{2}$, and such excursions must thus be seen as direct consequences of the overall 'secular' variation of the dipole field.

Received 11 January; accepted 29 March 1999.

1. Guyodo, Y. \& Valet, J.-P. Relative variations in geomagnetic intensity from sedimentary records: the past 200,000 years. Earth Planet. Sci. Lett. 143, 23-36 (1996).

2. Frank, M. et al. A $200 \mathrm{kyr}$ record of cosmogenic radionuclide production rate and geomagnetic field intensity from ${ }^{10} \mathrm{Be}$ in globally stacked deep-sea sediments. Earth Planet. Sci. Lett. 149, 121-129 (1997).

Tric, E. et al. Paleointensity of the geomagnetic field for the last 80,000 years. J. Geophys. Res. 97, 9337 9351 (1992).

4. Meynadier, L., Valet, J.-P., Weeks, R., Shackleton, N. \& Hagee, V. L. Relative geomagnetic intensity of the field during the last $140 \mathrm{ka}$. Earth Planet. Sci. Lett. 114, 39-57 (1992).

5. Tauxe, L. \& Wu, G. Normalised remanence in sediments from western equatorial Pacific: relative paleointensity of the geomagnetic field. J. Geophys. Res. 95, 12337-12350 (1990).

6. Tauxe, L. \& Shackleton, N. J. Relative paleointensity records from the Ontong-Java Plateau. Geophys. J. Int. 117, 769-782 (1994).

7. Yamazaki, T. \& Ioka, N. Long-term secular variation of the geomagnetic field during the last $200 \mathrm{k} . \mathrm{y}$. recorded in sediment cores from the western equatorial Pacific. Earth. Planet. Sci. Lett. 128, 527-544 (1994).

8. Lehman, B. et al. Relative changes of the geomagnetic field intensity during the last 280 kyear from piston cores in the Acores area. Phys. Earth Planet. Inter. 93, 269-284 (1996).

9. Schneider, D. A. Late Pleistocene and Holocene geomagnetic intensity variations recorded in Sulu Sea sediments. Eos (suppl.) 75, S119 (1994).

10. Stoner, J. S., Channell, J. E. T. \& Hillaire-Marcel, C. A 200 ka chronostratigraphy for the Labrador Sea: Indirect correlation of the sediment record to SPECMAP. Earth. Planet. Sci. Lett. 159, 165-181 (1998).

11. Channell, J. E. T., Hodell, D. A., McManus, J. \& Lehman, B. Orbital modulation of the Earth's magnetic field intensity. Nature 394, 464-468 (1998).

12. Valet, J.-P., Meynadier, L., Bassinot, F. \& Garnier, F. Relative paleointensity across the last geomagnetic reversal from sediments of the Atlantic, Indian and Pacific Oceans. Geophys. Res. Lett. 21, 485-488 (1994).

13. Schneider, D. A. \& Mello, G. A. A high-resolution marine sedimentary record of geomagnetic intensity during the Brunhes Chron. Earth Planet. Sci. Lett. 144, 297-314 (1996).

14. Yamazaki, T., Ioka, N. \& Eguchi, N. Relative paleointensity of the geomagnetic field during the Brunhes Chron. Earth Planet. Sci. Lett. 136, 525-540 (1995).

15. Meynadier, L., Valet, J.-P., Bassinot, F., Shackleton, N. \& Guyodo, Y. Asymmetrical saw-tooth pattern of the geomagnetic field intensity from equatorial sediments in the Pacific and Indian Oceans. Earth Planet. Sci. Lett. 126, 109-127 (1994).

16. Meynadier, L. \& Valet, J.-P. Relative geomagnetic intensity during the last $4 \mathrm{~m} . \mathrm{y}$. from the equatorial Pacific. Proc. ODP Sci. Res. 138, 779-795 (1995).
17. Meynadier, L., Valet, J.-P., Guyodo, Y. \& Richter, C. Saw-toothed variations of relative paleointensity and cumulative viscous remanence: Testing the records and the model. J. Geophys. Res. 103, 70957105 (1998).

18. Guyodo, Y., Richter, C. \& Valet, J.-P. Paleointensity record from the Pleistocene sediments (1.4-0 Ma) off the California Margin. J. Geophys. .Res. (in the press).

19. Kent, D. V. \& Opdyke, N. D. Paleomagnetic field intensity recorded in a Brunhes epoch deep-sea sediment core. Nature 266, 156-159 (1977).

20. Bassinot, F. C. et al. The astronomical theory of climate and the age of the Brunhes-Matuyama magnetic reversal. Earth Planet. Sci. Lett. 126, 91-108 (1994).

21. Martinson, D. G. et al. Age dating and the orbital theory of the Ice Ages: development of a highresolution 0 to 300,000-year chronostratigraphy. Quat. Res. 27, 1-29 (1987).

22. Merill, R. T., Mc Elhinny, M. W. \& McFadden, P. L. (eds) The Magnetic Field of the Earth (Int. Geophysics Ser., Academic, London, 1998).

23. Valet, J.-P. \& Meynadier, L. Geomagnetic field intensity and reversals during the past four million years. Nature 366, 91-95 (1993)

24. Merill, R. T. \& McFadden, P. L. Geomagnetic stability: Reversal events and excursions. Earth Planet. Sci. Lett. 121, 57-69 (1994).

25. Langereis, C. G., Dekkers, M. J., de Lange, G. J., Paterne, M. \& van Santvoort, P. J. M. Magnetostratigraphy and astronomical calibration of the last $1.1 \mathrm{Myr}$ from an eastern Mediterranean piston core and dating of short events in the Brunhes. Geophys. J. Int. 129, 75-94 (1997).

26. Quidelleur, X., Gillot, P. Y. \& Carlut, J. Link between excursions and paleointensity inferred from abnormal field directions recorded at La Palma around $600 \mathrm{ka}$. (suppl.) 78, F181 (1997).

27. Champion, D. E., Lanphere, M. A. \& Kuntz, M. A. Evidence for a new geomagnetic reversal from lava flows in Idaho: Discussion of short polarity reversals in the Brunhes and late Matuyama polarity chrons. J. Geophys. Res. 93, 11667-11680 (1988).

28. Worm, H.-U. A link between geomagnetic reversals, events and glaciations. Earth Planet. Sci. Lett. 177, 55-67 (1997)

29. Malkus, W. V. R. Precession of the earth as the cause of geomagnetism. Science 160, 259-264 (1968). 30. Wollin, G., Ericson, D. B. \& Ryan, W. B. F. Magnetism of the earth and climatic changes. Earth Planet. Sci. Lett. 12, 171-183 (1971)

31. Creer, K. M., Thouveny, N. \& Blunk, I. Climatic and geomagnetic influences on the Lac du Bouchet paleomagnetic record through the last 110,000 years. Phys. Earth Planet. Inter. 64, 314-341 (1990).

32. Vanyo, J. P. A geodynamo powered by luni-solar precession. Geophys. Astrophys. Fluid Dyn. 59, 209234 (1991)

33. Paillard, D., Labeyrie, L. \& Yiou, P. Macintosh program performs time-series analysis. Eos 77, 379 (1996).

Supplementary information is available on Nature's World-Wide Web site (http://www.nature.com) or as paper copy from the London editorial office of Nature.

Acknowledgements. We thank J. E. T. Channell, C. Laj, L. Meynadier, D. A. Schneider, J. S. Stoner, L. Tauxe and T. Yamazaki for supplying data, and F. C. Bennett for comments. This work was supported by the CNRS-INSU program Intérieur de la Terre. At this University of Florida, Y.G. was supported by a grant awarded to J. E. T. Channell.

Correspondence and requests for material should be addressed to Y.G. (e-mail: guyodo@ufl.edu). Data from sites 983 and 984 are available from J.E.T. Channell at the University of Florida (e-mail: jetc@nerdc.ufl.edu).

\section{Nature of the Earth's earliest crust from hafnium isotopes in single detrital zircons}

\author{
Yuri Amelin ${ }^{\star}$, Der-Chuen Lee $\dagger$, Alex N. Halliday $\ddagger$ \\ \& Robert T. Pidgeon $\$$
}

* Department of Earth Sciences, Royal Ontario Museum, Toronto,

Ontario M5S 2C6, Canada

$\dagger$ Department of Geological Sciences, University of Michigan, Ann Arbor, Michigan 48109, USA

¥Department of Earth Sciences, ETH, Zurich, CH-8092, Switzerland

$\$$ School of Applied Geology, Curtin University of Technology, Bentley, WA 6102, Australia

Continental crust forms from, and thus chemically depletes, the Earth's mantle. Evidence that the Earth's mantle was already chemically depleted by melting before the formation of today's oldest surviving crust has been presented in the form of Sm-Nd isotope studies of 3.8-4.0 billion years old rocks from Greenland $^{1-5}$ and Canada $\mathrm{C}^{5-7}$. But this interpretation has been questioned because of the possibility that subsequent perturbations may have re-equilibrated the neodymium-isotope compositions of these rocks $^{8}$. Independent and more robust evidence for the origin of the earliest crust and depletion of the Archaean mantle can potentially be provided by hafnium-isotope compositions of zircon, a mineral whose age can be precisely determined by $\mathrm{U}-\mathrm{Pb}$ dating, and which can survive metamorphisms ${ }^{4}$. But the amounts of hafnium in single zircon grains are too small for the isotopic composition to be precisely analysed by conventional methods. 